\title{
From Motivation to Activation: Why Engaged Workers are Better Performers
}

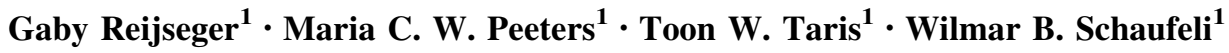

Published online: 10 March 2016

(c) Springer Science+Business Media New York 2016

\begin{abstract}
Purpose The purpose of this study was to investigate the relationship between work engagement and multiple dimensions of employee performance, as mediated by open-mindedness.

Design/Methodology/Approach Survey data were obtained from 186 employees of a food processing plant and the findings were cross-validated in an independent convenience sample $(N=308)$.

Findings SEM analyses revealed that the more engaged the employees were, the more they displayed extra-role and in-role performance. As expected, these associations were partially mediated by open-mindedness. Results were ambiguous for counterproductive performance showing a direct negative relation between engagement and counter productivity, and an indirect, positive relation through open-mindedness.

Implications With its systematic look at the relation between engagement and multiple indicators of performance, the current study shows why it is important for both employers and employees to invest in engaged employees: there is a relationship with better performance which can partly be explained by the fact that engagement is associated with open-mindedness. This may help to inform organizations under what circumstances engagement leads to positive or negative forms of performance. Vice versa, a decrease in the multiple indicators of performance may
\end{abstract}

Gaby Reijseger

G.Reijseger@uu.nl

1 Department of Work and Organizational Psychology, Utrecht University, P.O. Box 80.140, NL-3508 Utrecht, The Netherlands signal organizations to look after their employees' mental health, i.e., engagement.

Originality/Value This is one of the first studies to include multiple dimensions of employee performance in relation to work engagement. Moreover, it is one of the first studies that focus on the underlying psychological process that might explain for this relationship.

Keywords Work engagement - Employee well-being · Open-mindedness $\cdot$ Job performance $\cdot$ Extra-role behavior . In-role behavior . Counterproductive behavior .

Organizational outcomes

An increasing number of studies confirms that employee work engagement-a positive affective-cognitive workrelated state of mind characterized by vigor, dedication, and absorption (Schaufeli and Bakker 2004)—is worth striving for both for employees (Bakker et al. 2008) and organizations (Christian et al. 2011). Engagement is associated with fewer health problems (Bakker et al. 2011 for an overview), less absenteeism (Darr and Johns 2008), lower actual turnover (Wright and Bonett 2007), and above all, higher performance (Christian et al. 2011). However, less attention has been given to the mechanisms accounting for the relations between work engagement and different types of positive outcomes. In the present study, we focus specifically on job performance, and although it seems intuitively evident, on the yet unanswered question why engaged workers perform better than non-engaged workers. The current study aims to fill this gap by investigating a potential underlying, explaining mechanism in this relation. Moreover, in linking engagement to performance, we also make a distinction between different types of performance. In line with the previous literature reviews 
(Koopmans et al. 2011; Reijseger et al. 2012), we focus upon in-role, extra-role, and counterproductive behavior.

\section{How Engagement can Promote Performance: an Affective-Cognitive Approach}

Several studies have examined the association between work engagement and performance. For instance, in their quantitative review of 91 studies, Christian et al. (2011) confirmed that highly engaged employees scored better on task performance (i.e., in-role behavior) than their less engaged colleagues. In addition to performing better on the task, Bakker and Bal (2010) showed that engaged employees also seemed to help others more, took more initiative, and were more creative (i.e., extra-role behavior). Finally, several studies showed that higher negative affect lead to more counterproductive work behavior (Balducci et al. 2011; Penney and Spector 2005). Moreover, Balducci et al. (2011) found a negative correlation between work engagement and counter productivity. These studies indicate that, when thinking of affect as a continuum from negative to positive, engaged workers are less likely to be counterproductive at work. Thus, in line with previous findings, we firstly hypothesize that work engagement associates positively with extra-role behavior (Hypothesis 1a) and in-role behavior (Hypothesis 1b), but negatively with counterproductive work behavior (Hypothesis 1c).

Although previous research has paid little empirical attention to the mechanisms accounting for the relation between engagement and performance, scholars did reason why engaged workers would perform better than others (Bakker and Demerouti 2008). For example, it has been argued that engaged workers are better able to focus more on the tasks at hand due to more social resources and a better health. Also, it might be that engaged workers are more willing to perform well. That is, engaged workers are both able and motivated to do a good job. They are happily engrossed in their work (i.e., affect), whereby time passes quickly and they have difficulty detaching themselves from work (i.e., cognition) (Schaufeli and Bakker 2004).

From an affective point of view, it can be argued that being engaged at work often coincides with a domainspecific state of happiness likely to be attained when positive emotions are experienced (Ouweneel et al. 2012). Typical positive emotions that engaged worker's experience are pride, enthusiasm, and joy (Schaufeli and Van Rhenen 2006). As Fredrickson (2001) theorizes in her Broaden-and-Build Theory, the experience of such positive emotions enables people to broaden their thinking and build upon that widened array of thoughts. In line with this, it can be expected that engaged workers will open up their minds which facilitates broadened thinking and enhances extensive exploration of relevant information in the work environment and the amount of effort put into one's work activities (Brown and Leigh 1996). One might speculate that engaged workers build their knowledge, skills, and abilities upon this broadened, open-minded thinking and thus expand their thought-action repertoire. Roe (1999) indicates that broadening, or opening up, one's mind due to a domain-specific state of happiness (such as work engagement) benefits one's performance.

Besides being energized and dedicated (Schaufeli and Bakker 2004), engaged workers are also cognitively absorbed by what they do. We know from previous work (Van Beek et al. 2012) that work engagement is best maintained when instigated by intrinsic motivation. However, what specific type of intrinsic motivation may explain for their increased performance of engaged workers is still rather unknown. As work often involves a lot of information processing and deciding upon that information, we focus in the current study on employees' need to develop a full and accurate understanding of their environment, i.e., epistemic motivation (Kruglanski and Webster 1996).

Epistemic motivation entails the need to develop a full and accurate understanding of the world, gaining knowledge for reasoned actions (Kruglanski, 1980). People low in epistemic motivation have a high need to come to decisions and actions quickly, closing one's mind from other, potentially relevant information (Kruglanski and Webster 1996), whereas people high in epistemic motivation have an open mind toward new and relevant information to gain a full and accurate understanding of their work. No matter how complex the information may be, people who are highly motivated to process such new, potentially complex information (i.e., highly openminded) are more inclined to decide and act upon that information (Amit and Sagiv 2013), which could improve their performance. For instance, a study by De Dreu et al. (2006) showed that negotiators who were high in epistemic motivation displayed higher proactive problemsolving behavior-compared to those low in epistemic motivation-leading to better final results for the first group.

Thus, based on both Broaden-and-Build theory (Fredrickson 2001) and epistemic motivation theory (Kruglanski 1980), the current study assumes that work engagement nourishes an open mind toward potentially relevant information regarding employees' work tasks, which, in turn, leads to higher job performance. Put differently, we hypothesize that a state of engagement fosters open-mindedness (Hypothesis 2). We define open-mindedness at work as the extent to which one is receptive to new relevant information and consequently has the stance, willingness, and/or preparedness to move to action. 


\section{From Open-Mindedness to Performance}

Previous literature shows that open-mindedness is related to different forms of process performance (i.e., those particular actions or behaviors that people undertake to arrive at their final products or services; Roe 1999). Specifically, it is known that open-mindedness is positively related to extra-role performance (MacKenzie et al. 1993) such as innovativeness (Tjosvold et al. 2004) and creativity (Chirumbolo et al. 2005). Tjosvold et al. (2004), for instance, found that teams who are highly motivated to process relevant information (i.e., being open-minded or epistemically motivated) and adapt their team's objectives, strategies, and processes based on that information, showed greater innovativeness than teams who were less epistemically motivated. Furthermore, Chirumbolo et al. (2005) found in several experiments that individuals high in epistemic motivation (i.e., highly open-minded) were much more creative in their interaction with others when trying to solve a problem than those low in epistemic motivation. The highly open-minded individuals, for instance, suggested more alternative solutions to problems and came up with more, new ideas.

Thus, problem-solving decision behavior often refers to out-of-the-box thinking, acting upon complex information even outside of one's comfort zone (Amit and Sagiv 2013), and collaborating with others to arrive at joint outcomes (Chirumbolo et al. 2005). These behaviors are all forms of those discretionary behaviors of an employee who directly promotes the effective functioning of an organization, also called extra-role behavior (MacKenzie et al. 1993). Following from this work, we hypothesize that open-mindedness positively relates to extra-role behavior (Hypothesis 3a).

Of course, problem-solving decision behavior may not only be relevant for extra-role behavior, but it is also part of one's formally required behavior at work, called in-role behavior (Motowidlo and Van Scotter 1994). In addition to the enhancement of all kinds of extra-role behavior by open-mindedness (De Dreu et al. 2006; Galinsky and Kray 2004), it has also been found that processing of information results in better in-role performance (Fujita et al. 2007). Moreover, the conflict literature suggests that, as long as open-mindedness at work is facilitated, employees tend to confront each other constructively, and do not withdraw in destructive, counterproductive behavior (Tjosvold 2008). These counterproductive behaviors concern voluntary behavior that violates significant organizational norms and in doing so threatens the well-being of an organization, its members, or both (Robinson and Bennett 1995). Although little research has been done on epistemic motivation and counterproductive behavior so far, it seems plausible that when employees are receptive to new, relevant information for the execution of their job, they are not likely to engage into counter productivity such as longer breaks and avoiding work. Thus, besides the assumed relation between open-mindedness and extra-role behavior, we expect openmindedness to relate positively to in-role behavior (Hypothesis $3 \mathrm{~b}$ ), and negatively to counterproductive work behavior (Hypothesis 3c).

\section{The Present Study}

While the previous literature has mostly focused on the direct relation between work engagement and performance, certain theoretical premises (i.e., Broaden-and-Build theory, epistemic motivation) might suggest that this relation can be explained in more detail by an underlying mechanism called open-mindedness. The current study examines this explanatory mechanism in two different samples, helping us to gain knowledge on the question why engaged workers are better performers. Insight in this mechanism will contribute to the development of more theory grounded interventions on engagement and performance. Moreover, rather than focusing on one type of process performance, we incorporate the three dimensions of process performance; extra-role, in-role, and counterproductive behaviors. In addition to the three bi-variate hypotheses, we formulate the following three mediation hypotheses:

Hypothesis 4a: Open-mindedness partially mediates the positive relation between work engagement and extra-role behavior.

Hypothesis 4b: Open-mindedness partially mediates the positive relation between work engagement and in-role behavior.

Hypothesis 4c: Open-mindedness partially mediates the negative relation between work engagement and counterproductive work behavior.

\section{Method}

\section{Participants and Procedure}

In order to test the hypotheses, an online survey study was conducted across two different samples, a homogeneous and a heterogeneous sample.

Sample 1 consisted of 541 employees of an international food processing plant located in the Netherlands. All employees were personally invited to voluntarily participate in this study as part of an occupational health survey 


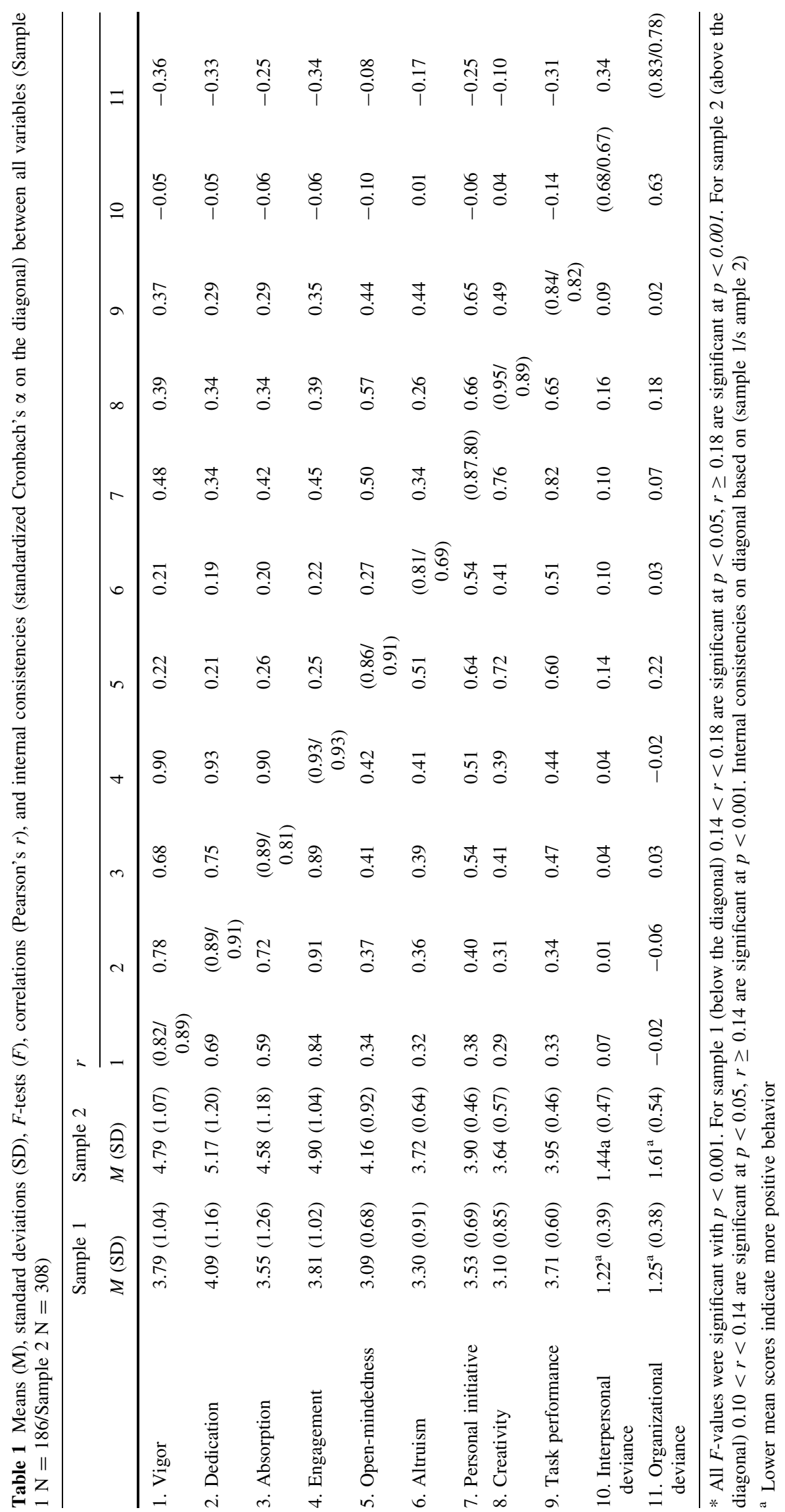


through a letter that was sent to their home address. The online link to the web-based questionnaire could be used on any computer with access to the internet. Six computers were made accessible at a central location in the plant for all employees without internet access at their job. $34 \%$ of the employees completed the survey $(N=186)$. Of this sample, $76.9 \%$ was male, $M_{\text {age }}$ was 46 years $(\mathrm{SD}=$ 10.70), and the majority held a lower to intermediate-level vocational degree (52\%), a higher level vocational degree $(23 \%)$, or a university degree $(13 \%)$.

Sample 2 was a convenience sample and included respondents from various organizational sectors. Data were collected through an open, online survey on the website of a large Dutch company, delivering services in the fields of organizational consultancy, coaching and training. 308 employees participated and completed the survey. Most of the participants were employees who worked in health care $(25 \%)$, retail (14\%), and customer-related services (8\%), respectively. The sample included 119 males $(38.6 \%)$ and the mean age was 43 years $(\mathrm{SD}=11.49)$. The majority of this sample held a higher vocational training (39\%) or a university degree $(31 \%)$.

Since these samples differ in sex, age, and educational level, it allows us to cross-validate our results across a homogeneous (sample 1) and heterogeneous sample (sample 2). In order to maintain all other conditions as equal as possible across both samples, all participants answered the same online survey. Employees were first briefly introduced to the study in which the anonymity and confidentiality of the data were emphasized.

\section{Measures}

Table 1 presents the internal consistencies (Cronbach's $\alpha$ ) and intercorrelations for the study variables for both Samples 1 and 2. All scales meet Nunnally and Bernstein's (1994) criterion for acceptable internal consistency (Cronbach's $\alpha \mathrm{s} \geq 0.70$ ). Only the value for interpersonal deviance is slightly lower $(0.68 / 0.67)$.

\section{Work engagement}

The shortened version of the Utrecht Work Engagement Scale (UWES; Schaufeli et al. 2006) assessed work engagement, as reflected in its three dimensions vigor, dedication, and absorption. All subscales consisted of three items; Vigor (VI); e.g., "When I get up in the morning, I feel like going to work," Dedication (DE); e.g., "I am enthusiastic about my job," and Absorption (AB); e.g., "I feel happy when I am working intensely" $(0=$ 'never,' $6=$ 'always').

\section{Open-Mindedness}

For the purpose of this study, a new scale was developed to measure an individual's state of open-mindedness. For this scale, eight items (Table 2) were developed, based on the closed mindedness dimension of Webster and Kruglanski's Need for Closure scale (1994) and the open-mindedness scale of the Multi-Cultural Personality Questionnaire (MPQ) of Van der Zee and Van Oudenhoven (2000). The authors adapted the items of both these original scales in three steps. First, based on face validity, the authors marked the items of both scales that were applicable to the work context. Secondly, after assorting which items the authors all agreed upon as being applicable, the items were altered to the work context (for instance by integrating 'at work' or 'compared to coworkers'). Finally, all authors checked the items for readability and polished items together wherever necessary, finalizing the definite scale (Table 2). Participants could answer the items on a fivepoint frequency scale $(1=$ 'never,' $5=$ 'always').

Before using the open-mindedness scale in testing the hypotheses, the factor structure of the scale was explored. Assuming that the measure of open-mindedness entails a one-dimensional construct, we used a principal component analysis (PCA) to first check whether the sample size was adequate for the analysis using the Kaiser-Meyer-Olkin (KMO) measure. For the overall scale, the KMO was 0.88 ; moreover, the KMO for all individual items was 0.84 or higher, thus satisfying the requirement that all KMO values should exceed 0.50 (Field 2009) to indicate an adequate sample size. The PCA with oblimin rotation across Sample 1 initially indicated that the open-mindedness scale consisted of two factors with eigenvalues larger than 1.0. However, the first factor explained four times the amount of unique variance compared to the second factor. Moreover, all items loaded reasonably high on both factors (see Table 2 for factor loadings, eigenvalues, and Cronbach's as). To further clarify whether the structure of the openmindedness scale consisted of one or two dimensions, a confirmatory factor analysis (CFA) across Sample 2 compared a one-factor to a two-factor model (with the factors based on the PCA of Sample 1). While both models fitted the data very well, $\chi^{2}(N=308, d f=20)=45.7$, $\mathrm{CFI}=0.98$, TLI $=0.97$, and RMSEA $=0.07$ for the onefactor model and $\chi^{2}(N=308, \quad d f=19)=42.9$, $\mathrm{CFI}=0.98$, TLI $=0.97$, and RMSEA $=0.06$ for the twofactor model, the CFA signaled a nearly perfect linear dependency between the two factors of the two-factor model, resulting from a not positive definite input covariance matrix. The latter suggests that a one-factor solution for the open-mindedness is probably the best solution for 
Table 2 Items of the open-mindedness scale

\begin{tabular}{|c|c|c|}
\hline \multirow[t]{2}{*}{ Items } & \multicolumn{2}{|c|}{ Factor loadings } \\
\hline & Factor 1 & Factor 2 \\
\hline 1. When considering most conflict situations at work, I can usually see how both sides could be right & 0.73 & 0.33 \\
\hline 2. Whenever I'd like advise about a problem at work I prefer to consult co-workers who usually think differently from me & 0.39 & 0.74 \\
\hline 3. I always see many possible solutions to problems I face at work & 0.74 & 0.64 \\
\hline 4. I am prepared to work in a different way, even if it differs a great deal from my own way of working & 0.22 & 0.81 \\
\hline 5. At work I invest a lot of energy in finding the right solutions to problems & 0.84 & 0.28 \\
\hline 6. Whenever possible, I apply new procedures of working to do my job. & 0.82 & 0.53 \\
\hline 7. At work I would go all the way for a different working method if that seems to be a better method & 0.49 & 0.76 \\
\hline 8. New ideas at work get me going & 0.60 & 0.71 \\
\hline Eigenvalue & 4.02 & 1.04 \\
\hline$\%$ of variance & 50.28 & 12.98 \\
\hline$\alpha$ & 0.81 & 0.77 \\
\hline
\end{tabular}

the open-mindedness scale. Table 1 shows that the reliability of this scale was high in both samples (Cronbach's $\alpha$ s were 0.86 and 0.91 ).

\section{Job Performance}

Extra-role behavior was measured with three different scales commonly used in the literature to measure specific types of extra-role behavior. The first indicator-altruism of the organizational citizenship behavior questionnaire (OCB; Lievens and Anseel 2004; Smith et al. 1983)consisted of three items, e.g., "I help co-workers who have heavy workloads" ( $1=$ 'never,' $5=$ 'always'). The second indicator-personal initiative was measured with Frese et al.'s personal initiative scale (1997). This scale consists of seven items, such as "Usually I do more than I'm asked to do." Finally, the third indicator-creativity was measured with a shortened version of the Creativity scale (Zhou and George 2001). The original 13 items of the scale were reviewed in terms of their applicability in all types of jobs and organizations. Seven out of these 13 items measured creativity in a more generalized manner and could be used across different organizational sectors, e.g., "In my work I come up with new and practical ideas to improve performance." All items of extra-role behavior were measured on a five-point frequency scale $(1=$ 'never,' $5=$ 'always') and showed high reliability (Table 1 ).

In-role behavior consisted of nine items based on Goodman and Svyantek's (1999) task performance scale, e.g., "I fulfill all the requirements of my job." Similar to extra-role behavior, the items of in-role behavior were measured on a five-point frequency scale $(1=$ 'never,' 5 = 'always').

Counterproductive behavior was measured with two different scales (interpersonal and organizational deviance, respectively: Robinson and Bennett 1995) that have frequently been used in previous studies on counterproductive work behavior. Interpersonal deviance was measured with four items, chosen from Robinson and Bennett's (1995) list of deviant behaviors. These items measured minor deviant behaviors such as "I said something hurtful to someone at work" rather than serious personal aggression. From the list of deviant behaviors, nine items tapping organizational deviance were selected. In consideration of the wishes of the organization (Sample 1) and to avoid socially desirable answering, these items also measured only minor deviant behaviors, focusing on production deviance rather than property deviance, such as "The past month at work I spent too much time fantasizing or daydreaming instead of working" ( 1 = 'never,' $5=$ 'always').

\section{Data Analyses}

In line with Conway and Lance's (2010) recommendations regarding addressing common method variance, confirmatory factor analyses first tested whether the openmindedness scale could be distinguished from relating constructs in the research model at the item level. On a second-order level, a confirmatory factor analysis investigated whether all constructs-work engagement, openmindedness, extra-role behavior, in-role behavior, and counterproductive work behavior-could be distinguished from each other. After the confirmatory factor analyses, the hypothesized mediation model was tested. Potential differences in hypothesized relations were again cross-validated in a multiple group analysis.

All model tests were based on the structural equation modeling (SEM) methods using maximum-likelihood estimation as implemented in AMOS (Arbuckle, 1997). In order to reduce model complexity, the nine task performance items were randomly assigned to three parcels of three items each (Bandalos, 2002). Similarly, the items of 
organizational deviance were randomly assigned to two parcels. The fit of all models to the data was examined with the $\chi^{2}$ goodness-of-fit statistic, the Root Mean Square Error of Approximation (RMSEA), the Tucker-Lewis Index (TLI), and the Comparative Fit Index (CFI). Generally, models with TLI and CFI $>0.90$, and RMSEA $<0.08$ represent a close fit between the hypothesized model and the data (Hoyle 1995).

\section{Results}

\section{Preliminary Analyses}

First, it was checked if open-mindedness can empirically be distinguished from the other study variables. In both samples, we ran CFA's comparing a one-factor model with a two-factor model. The results presented in Table 3 show that open-mindedness can indeed be empirically distinguished from altruism, creativity, personal initiative, and the three dimensions of work engagement.

Next, it was examined whether the five study variables could empirically be distinguished from each other. Five different models were compared in both samples (see Table 4). Table 4 shows that both the four- and the fivefactor model provided good fit to the data. However, the five-factor model fitted the data significantly better than the four-factor model, $\Delta \chi^{2} \quad(N=186, d f=4)=24.55$, $p<0.01$. Thus, all the items that were used in the present study could be assigned to five empirically and theoretically distinct factors.

In an additional series of multiple-group confirmatory factor analyses, we determined whether the parameters of the best-fitting model (model $\mathrm{M}_{5}$ ) were invariant across Sample 1 and Sample 2. All corresponding factor loadings (Fig. 1) were constrained to be equal across the two samples. Both the unconstrained and constrained model fitted the data quite well (Table 4). Constraining the factor loadings across samples revealed a significant but small increase of the Chi-square value, $\Delta \chi^{2} \quad(N=186$, $\Delta d f=8)=18.46, p=0.02$, indicating minor differences in factor loadings across the two samples. Constraining each separate factor loading to be equal revealed that the factor loadings of two indicators of counterproductive work behavior differed across the samples, $\Delta \chi^{2}(N=186$, $\Delta d f=6)=16.59, p=0.02$, for interpersonal deviance, and $\Delta \chi^{2}(N=186, \Delta d f=6)=15.81, p=0.02$, for the first parcel of organizational deviance.

In conclusion, there are no differences in factor loadings across the two samples for the indicators of extra-role and in-role behavior. However, the factor loadings for the indicators of counterproductive work behavior varied slightly across samples. However, as Table 4 displays, none of the fit indices differed greatly from one another, including the GFI (0.909 for unconstrained, 0.905 for constrained model), the NFI (0.904 for unconstrained, 0.898 for the constrained model), and the IFI ( 0.935 for unconstrained, 0.931 for constrained model). Therefore, in spite of the minor differences concerning the fit of the models, we conclude that the underlying factor structure was similar across samples.

\section{Testing the Research Model}

Bootstrapping techniques were used to examine the fit of the data to the full mediation model with only indirect relations $\left(\mathrm{M}_{\mathrm{ind}}\right)$, and to compare the fit of this model to that of models with only direct $\left(\mathrm{M}_{\mathrm{dir}}\right)$ relations and both direct and indirect relations $\left(\mathrm{M}_{\mathrm{bo}}\right)$ in order to test for (partial) mediation in Sample 1. The full mediation model $\left(\mathbf{M}_{\text {ind }}\right)$ fitted the data reasonably well with $\chi^{2}(N=186$, $d f=59)=154.4, \quad$ CFI $=0.93, \quad$ TLI $=0.91, \quad$ and RMSEA $=0.09$. However, the model with both $\left(\mathrm{M}_{\mathrm{bo}}\right)$ direct and indirect relations fitted the data best in comparison to the full mediation model $\left(\mathrm{M}_{\mathrm{ind}}\right) \Delta \chi^{2}(N=186$, $\Delta d f=3)=18.27, p<0.001$, and the model with only direct relations $\left(\mathrm{M}_{\mathrm{dir}}\right) \Delta \chi^{2}(N=186, \Delta d f=1)=35.48$, $p<0.001$. Moreover, the partial mediation model fitted the data well with $\chi^{2} \quad(N=186, \quad d f=56)=136.1$, $\mathrm{CFI}=0.94$, TLI $=0.92$, and RMSEA $=0.09$. In this model, all indicators loaded significantly on their intended latent factors and all effects were in the expected directions (Fig. 2).

In line with the expectations, the partial mediation model revealed that work engagement related positively to extra-role and in-role behavior both directly $(\mathrm{H} 1 \mathrm{a}, \mathrm{b})$ and through the mediating effect of open-mindedness $(\mathrm{H} 2, \mathrm{H} 4 \mathrm{a}$, b). Open-mindedness associated positively with both extrarole and in-role behavior, thereby supporting our hypotheses regarding these bi-variate relations $(\mathrm{H} 3 \mathrm{a}, \mathrm{b})$. However, work engagement related neither negatively nor positively to counterproductive work behavior, while openmindedness related positively to counterproductive work behavior, rejecting both hypotheses $1 \mathrm{c}$ and $3 \mathrm{c}$. Contrary to hypothesis 4c, open-mindedness indirectly related engagement to counterproductive work behavior, such that high work engagement was associated with high openmindedness, which, in its turn, associated with high levels of counterproductive behavior (Fig. 2).

Again, in an additional series of multiple-group path analyses, we determined whether the parameters of the final model were invariant across Sample 1 and Sample 2. Although the multigroup analysis mostly confirmed the predicted relations, the constrained model (regression weights $)$ with $\chi^{2}(N=186 / N=308, d f=120)=450.2$, $\mathrm{CFI}=0.90, \mathrm{TLI}=0.88$, and RMSEA $=0.07$, differed 
Table 3 Fit indices for the confirmatory factor analyses of the items of open-mindedness (OM) versus altruism (Alt), versus creativity (Crea), versus personal initiative (PI), and versus work engagement (WE) across two samples $(N=186, N=308)$

\begin{tabular}{|c|c|c|c|c|c|c|c|c|c|c|}
\hline Model step & $X^{2}$ & $d f$ & $p$ & CFI & RMSEA & TLI & $\Delta \_$models & $\Delta X^{2}$ & $\Delta d f$ & $p$ \\
\hline \multicolumn{11}{|l|}{ SEM_CFA $(N=186)$} \\
\hline M1_1factorAlt_\&_OM & 190.50 & 44 & $<0.001$ & 0.81 & 0.13 & 0.77 & & & & \\
\hline M2_2factorAlt_vs_OM & 94.42 & 43 & $<0.001$ & 0.94 & 0.08 & 0.92 & M1-M2 & 96.08 & 1 & $<0.001$ \\
\hline \multicolumn{11}{|l|}{ SEM_CFA $(N=308)$} \\
\hline M1_1factorAlt_\&_OM & 220.50 & 44 & $<0.001$ & 0.89 & 0.11 & 0.86 & & & & \\
\hline M2_2factorAlt_vs_OM & 80.20 & 43 & $<0.001$ & 0.98 & 0.05 & 0.97 & M1-M2 & 140.30 & 1 & $<0.001$ \\
\hline \multicolumn{11}{|l|}{ SEM_CFA $(N=186)$} \\
\hline M3_1factorCrea_\&_OM & 355.20 & 90 & $<0.001$ & 0.86 & 0.13 & 0.84 & & & & \\
\hline M4_2factorCrea_vs_OM & 232.23 & 89 & $<0.001$ & 0.93 & 0.09 & 0.91 & M3-M4 & 122.97 & 1 & $<0.001$ \\
\hline \multicolumn{11}{|l|}{ SEM_CFA $(N=308)$} \\
\hline M3_1factorCrea_\&_OM & 801.92 & 90 & $<0.001$ & 0.74 & 0.16 & 0.69 & & & & \\
\hline M4_2factorCrea_vs_OM & 298.41 & 89 & $<0.001$ & 0.92 & 0.09 & 0.91 & M3-M4 & 503.51 & 1 & $<0.001$ \\
\hline \multicolumn{11}{|l|}{ SEM_CFA $(N=186)$} \\
\hline M5_1factorPI_\&_OM & 277.45 & 90 & $<0.001$ & 0.84 & 0.11 & 0.81 & & & & \\
\hline M6_2factorPI_vs_OM & 165.59 & 89 & $<0.001$ & 0.93 & 0.07 & 0.92 & M5-M6 & 111.86 & 1 & $<0.001$ \\
\hline \multicolumn{11}{|l|}{ SEM_CFA $(N=308)$} \\
\hline M5_1factorPI_\&_OM & 451.75 & 90 & $<0.001$ & 0.82 & 0.11 & 0.79 & & & & \\
\hline M6_2factorPI_vs_OM & 192.60 & 89 & $<0.001$ & 0.95 & 0.06 & 0.94 & M5-M6 & 259.15 & 1 & $<0.001$ \\
\hline \multicolumn{11}{|l|}{ SEM_CFA $(N=186)$} \\
\hline M7_1factorWE_\&_OM & 754.41 & 119 & $<0.001$ & 0.64 & 0.17 & 0.59 & & & & \\
\hline M8_2factorWE_vs_OM & 402.31 & 118 & $<0.001$ & 0.84 & 0.11 & 0.82 & M7-M8 & 352.10 & 1 & $<0.001$ \\
\hline M9_4factorVi\&Ded\&Ab_vs_OM & 230.70 & 113 & $<0.001$ & 0.93 & 0.08 & 0.92 & M8-M9 & 171.61 & 5 & $<0.001$ \\
\hline \multicolumn{11}{|l|}{ SEM_CFA $(N=308)$} \\
\hline M7_1factorWE_\&_OM & 1687.88 & 119 & $<0.001$ & 0.56 & 0.21 & 0.50 & & & & \\
\hline M8_2factorWE_vs_OM & 457.34 & 118 & $<0.001$ & 0.91 & 0.10 & 0.89 & M7-M8 & 1230.54 & 1 & $<0.001$ \\
\hline M9_4factorVi\&Ded\&Ab_vs_OM & 345.75 & 118 & $<0.001$ & 0.94 & 0.08 & 0.92 & M8-M9 & 111.59 & 5 & $<0.001$ \\
\hline
\end{tabular}

$X^{2}$ chi-square, CFI comparative fit index, RMSEA root mean square error of approximation, TLI Tucker Lewis index. Figures including factor loadings are available upon request by the first author

Table 4 Fit indices for the confirmatory factor analyses and multigroup comparisons of all constructs in research model

\begin{tabular}{|c|c|c|c|c|c|c|}
\hline Model step & $\chi^{2}$ & $d f$ & $p$ & CFI & RMSEA & TLI \\
\hline SEM path analysis $(N=186)$ & 525.46 & 65 & 0.000 & 0.68 & 0.20 & 0.60 \\
\hline \multicolumn{7}{|l|}{ 1. M1_one factor } \\
\hline 2. M2_engagement/open-mindedness vs. process performance & 435.02 & 64 & 0.000 & 0.73 & 0.18 & 0.67 \\
\hline 3. M3_engagement, open-mindedness & 355.82 & 63 & 0.000 & 0.79 & 0.16 & 0.74 \\
\hline 4. M4_engagement, open-mindedness, positive \& negative process performance & 143.90 & 60 & 0.000 & 0.94 & 0.09 & 0.92 \\
\hline $\begin{array}{l}\text { 5. M5_engagement, open-mindedness, extra-role, in-role, \& counterproductive } \\
\text { behavior }\end{array}$ & 120.03 & 56 & 0.000 & 0.95 & 0.08 & 0.94 \\
\hline \multicolumn{7}{|l|}{ Multigroup SEM path analysis (sample 1: $N=186$; sample $2: N=308$ ) } \\
\hline Unconstrained model & 328.18 & 112 & 0.000 & 0.93 & 0.06 & 0.91 \\
\hline \multirow[t]{3}{*}{ Constrained model (factor loadings) } & 346.64 & 120 & 0.000 & 0.93 & 0.06 & 0.91 \\
\hline & $\Delta \chi^{2}$ & $\Delta d f$ & $p$ & $\Delta \mathrm{CFI}$ & $\triangle$ RMSEA & $\Delta \mathrm{TLI}$ \\
\hline & 18.46 & 8 & 0.02 & 0.00 & 0.00 & 0.00 \\
\hline
\end{tabular}

$\Delta \chi^{2}$ chi-square difference, RMSEA root mean square error of approximation, TLI Tucker Lewis index, CFI comparative fit index 


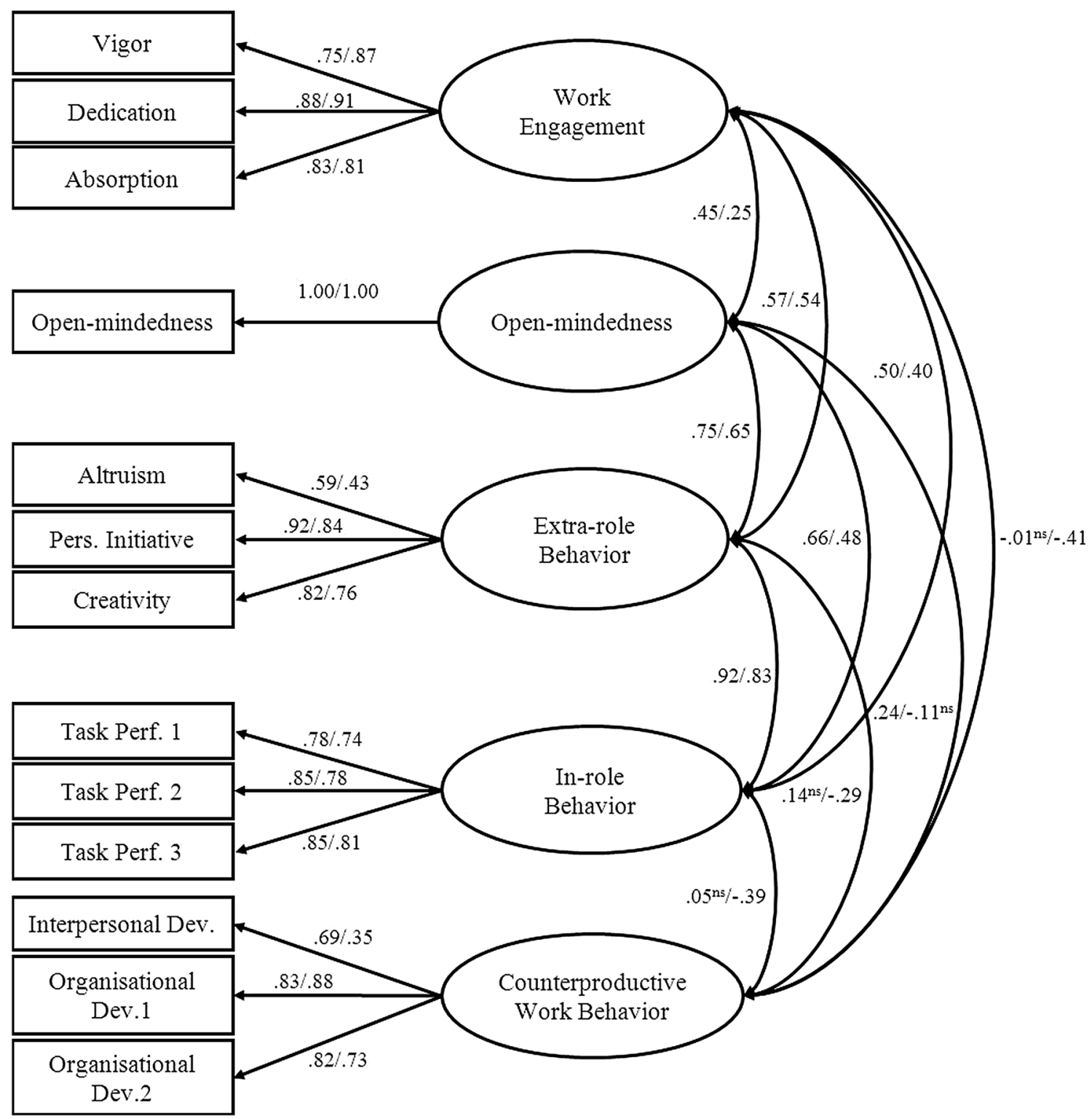

Fig. 1 CFA 5-factor model of all constructs based on sample 1 (first estimate)/sample 2 (second estimate)

significantly from the unconstrained model, $\Delta \chi^{2} \mathrm{M}_{\mathrm{con}}-$ $\mathrm{M}_{\text {unc }}(N=186 / N=308, \Delta d f=8)=25.4, \quad p=0.001$. Regarding the hypotheses, both Sample 1 and Sample 2 confirmed the expected direct positive relations between work engagement and open-mindedness (H2), between engagement and both extra-role (H1a) and in-role (H1b) behavior, and the positive relations between open-mindedness and extra-role (H3a) and in-role (H3b) behavior. These relations between engagement and process performance were partially mediated by open-mindedness in the expected positive direction across both samples (H4a, b). However, the groups (Samples 1 and 2) indicated ambiguous results for the relation between work engagement and counterproductive work behavior through openmindedness. While in the first sample, an indirect relation between engagement and counter productivity was found (with open-mindedness-contrary to Hypothesis 3c-being positively associated with counter productivity), in the second sample we found no significant effects between open-mindedness and counterproductive behavior, and only a direct, negative relation between work engagement and counterproductive work behavior in line with hypothesis $1 \mathrm{c}$ (but rejecting hypothesis $3 \mathrm{c}$ and $4 \mathrm{c}$ !).

\section{Discussion}

The present research investigated the relation between work engagement and job performance (i.e., extra-role, inrole, and counterproductive behavior), presenting an initial 


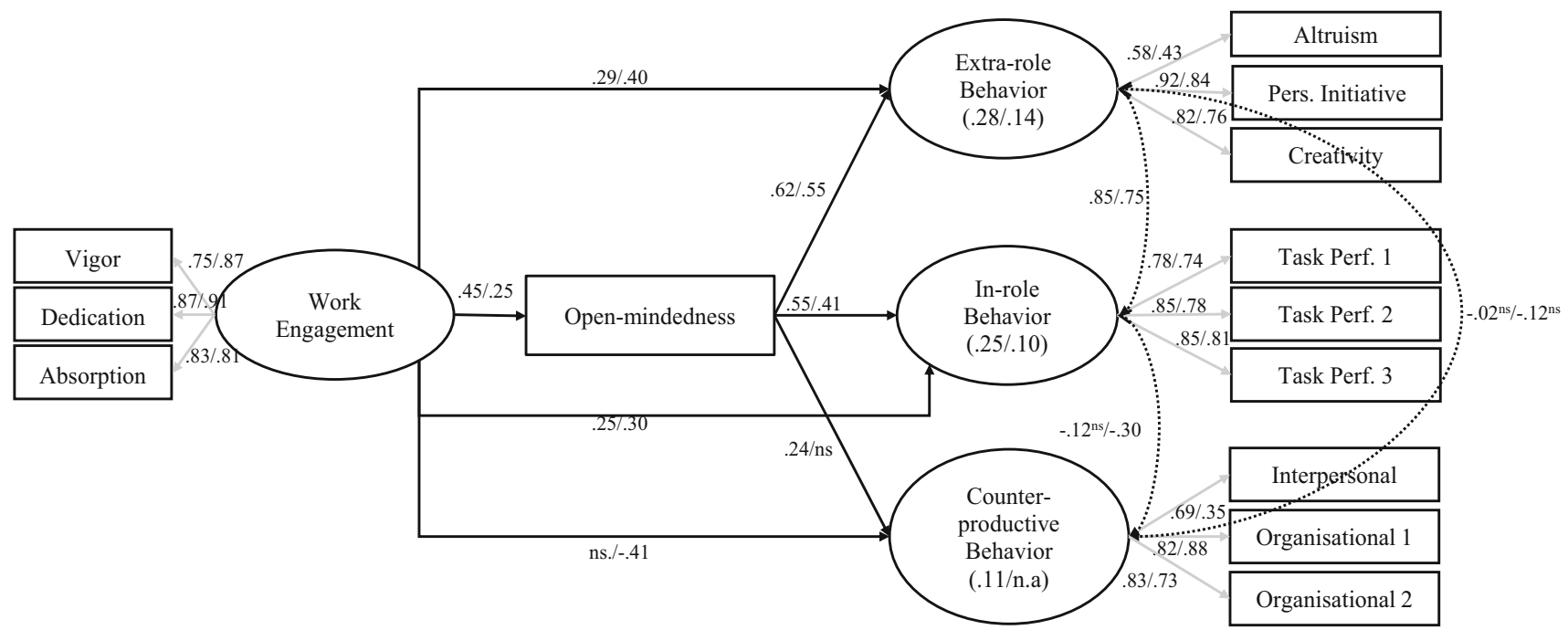

Fig. 2 Path analysis research model, regression weights for sample 1(first estimate)/sample 2 (second estimate). Indirect effects are mentioned for extra-role, in-role, and counterproductive behavior in the balloons for sample $1 /$ sample 2

underlying mechanism. In line with the assumptions, work engagement positively related to both in-role and extra-role performance across both the homogeneous and heterogeneous study groups. While in the heterogeneous group the expected negative relation between work engagement and counterproductive behavior was confirmed, the homogeneous group showed no such relation. Furthermore, the current study provided initial empirical evidence that the relation between work engagement and job performance is partly accounted for by the concept open-mindedness, i.e., the extent to which one is receptive to new relevant information and consequently has the stance, willingness, or preparedness to move to action. A newly developed scale revealed to be a valid and reliable, one-dimensional measure for employees' open-mindedness toward new and relevant information enabling them to exhibit positive behavioral performance. As such, this new scale proved to be a good scale to attend the current study's aim.

Investigating whether engaged workers were more open-minded compared to their non-engaged co-workers, consequently leading to more extra-role and in-role behavior and less counterproductive work behavior lead to some consistent conclusions. Firstly, the findings in this study indicate that work engagement and open-mindedness relate positively with each other. Furthermore, openmindedness is positively related to employees taking more initiative, helping colleagues, and doing their tasks with greater effectiveness.

On the other hand, some inconsistent findings obtained in this study force us to be inconclusive regarding the relation between work engagement and counter productivity. While the homogeneous sample suggested an indirect relation between engagement and counter productivity by open-mindedness, the heterogeneous sample solely indicated a direct negative relation between work engagement and counter productivity. While both samples indicated that more engagement also meant more openmindedness among employees, results suggested that openmindedness may also have unexpected negative effects. That is, employees may also be inclined to exhibit counterproductive work behaviors when they are open-minded. While engaged they may thus feel inclined to disregard some common, unwritten rules of their organization. Of course, as these results only apply to sample 1 and not to sample 2, the role of open-mindedness in the relation between engagement and counter productivity does not seem systematic. Further investigation and thoughts on theoretical implications are needed before drawing conclusions regarding these inconsistencies.

\section{Theoretical Implications}

Arising from the positive affective-cognitive state of work engagement based on Broaden-and-Build theory (Fredrickson 2001) and nourished by lay epistemic theory (Kruglanski 1989), the current study focused on the role of open-mindedness as an exploratory mechanism in the relation between engagement and performance. Partially mediating the relation between work engagement and extra-role and in-role behavior, findings are in line with previously found positive relations between actual exploratory behavior and extra-role and in-role behavior such as personal initiative (Frese et al. 1997) and individual creativity (Hirst et al. 2009). Similarly, this study confirmed previous findings on the assumed relation between one's receptiveness to new relevant information and 
problem-solving decision behavior in social interactions (De Dreu et al. 2006; Galinsky and Kray 2004), enhanced learning (De Dreu 2007), and innovativeness (Tjosvold et al. 2004). Thus, engaged employees indeed seem to broaden their thinking and build (Fredrickson 2001) upon newly acquired knowledge (Kruglanski 1989) by displaying more altruistic, initiative, creative, and functional task behaviors than their less engaged co-workers.

Contrary to what the conflict literature (Tjosvold 2008) would imply (namely that when open-mindedness at work is facilitated, employees tend to avoid conflict and withdrawal in destructive behavior), counterproductive work behavior could not unambiguously be anchored to low levels of work engagement through low levels of openmindedness. Intuitively one might speculate about the role of social desirability in explaining this puzzling result. However, a meta-analysis by Berry et al. (2012) found moderate to strong correlations between self- and otherrated counterproductive work behaviors. Moreover, similar patterns and magnitudes of relationships were found between a set of common correlates, such as job satisfaction and negative affect, and CWB regardless whether CWB was rated by others or by the self. So, social desirability does not seem to influence the results of counterproductive work behavior and an alternative explanation must be in play.

For instance, previous work found that employees high in negative affect performed more counterproductive work behavior than employees low in negative affect (Penney and Spector 2005). Perhaps, a negative state of mind would thus explain counterproductive work behavior better than taking only a positive affective state of mind into account. Particularly, taking negative affect toward the organization or managerial decisions into account in combination with work engagement may explain for the paradoxical positive relation between open-mindedness and counterproductive work behavior in one of the samples. Although employees may be highly engaged in their work, they may simultaneously disagree with the direction in which the organization is heading and thus experience negative affect toward the organization. Experiencing high open-mindedness due to high engagement could then lead to exhibition of behaviors normally seen as counterproductive, but in the eyes of the beholder, the employee, seen as highly productive going against managerial decisions regarding the organizational goals. Previous research reporting that positive affect increased counterproductive work behavior if job satisfaction was low (Duffy et al. 1998) supports the potential co-existence of positive and negative affect at work and its effect on negative performance.

Specifically, in organizations in which voicing one's thoughts and positive energy is not according to cultural norms, counterproductive work behavior could prosper while engagement, and open-mindedness consequently, is highly present. This would explain the ambiguous outcomes between the samples. It is known that when employees feel constrained to voice their positive thoughts and energy, these restrained thoughts and energy may be redirected into counterproductive work behavior (Meier and Spector 2013). Think for instance of an employee who has a good idea to improve task efficiency and he or she would like to take the initiative to test that idea. However, when a supervisor has no ears for such ideas the employee may feel constrained, which could lead to ignoring directions of one's supervisor (i.e., counterproductive work behavior). When testing to which degree voicing one's thoughts moderates the relation between work engagement and counter productivity in future research, it would be interesting to investigate the effects on interpersonal deviance and organizational deviance separately. The findings of current study support the notion on overlooked issues within the conceptualization of counterproductive work behavior (Bowling and Gruys 2010), suggesting that organizational deviance is more prone to be influenced by work engagement due to the fact that both notably refer to the work one is (not) doing. Interpersonal deviance on the other hand much more refers to teasing, bullying, or even conflict disregarding the employees' own work tasks and how these are affected completely.

Including other, negative forms of employee well-being in future research may also help to explain the unexpected finding that work engagement was positively related to counterproductive behavior through open-mindedness. We know for instance that stress is highly related to increased counterproductive work behavior (Penney and Spector 2005). More research on such negative forms of employee well-being in future studies may help unravel the ambiguous results of the two different samples in the current study even further.

Of course, there may be other underlying mechanisms appropriate to explain the relation between work engagement and the different types of job performance. The current study provided only one, preliminary explanation for the relation between work engagement and job performance, resulting in partial mediations. Besides that one can imagine that open-mindedness may be more relevant for some indicators of performance than for others, one can also think of many more concepts that could be involved in explaining the relation between work engagement and job performance (Bakker and Demerouti 2008). Alongside a cognitive explanation for the relation between work engagement and job performance, one may for instance think of more attitudinal or behavioral differences between engaged and non-engaged employees (Reijseger et al. 2012) that explain for differences in their job performance. Self-regulated or goal-directed behavior (Elliot and McGregor 2001) has for instance shown to affect 
performance in many different settings. Due to differences in goal-directed behavior, engaged workers may for instance mobilize their personal resources in a more fruitful way to perform well.

\section{Study Limitations}

The two most important limitations of this research are the cross-sectional design and the fact that we used self-reports for all study variables. Because of the cross-sectional design, no causal relations could be established. Longitudinal studies are needed to further validate the findings specifically regarding the mediation effects of open-mindedness (Taris and Kompier 2006). Moreover, such longitudinal investigations of the present research model should also shed light on the potential reciprocal effect between work engagement, open-mindedness, and job performance. Motivational theories such as Broaden-and-Build theory (Fredrickson 2001) seem to advocate that human behavior is a consequence of an intention or willingness to act, which is preceded by the individual's motivational state which is rooted in his or her affect and cognition. However, why employees exert certain behaviors is often a result of a much more dynamic relation between their experienced emotions, thoughts and intentions, as shown in work on reciprocal effects and gain spirals (i.e., Hakanen et al. 2008; cf. Taris and Kompier 2014). It is thus plausible to assume that work engagement and open-mindedness mutually reinforce each other, rather than being related one directionally. Further, longitudinal research is needed to reveal this potential reciprocal relation.

Furthermore, due to self-reports on all variables, common method bias may have biased the associations among the study concepts positively (Podsakoff et al. 2003). However, the lack of uniformly high correlations suggests that this bias is not very likely in the current study. Moreover, previous studies on the relation between work engagement and job performance as measured by supervisors and co-workers are in line with the findings presented here (Halbesleben and Wheeler 2008). Moreover, a meta-analysis by Gilboa et al. (2008) on the correlations between work stressors on the one hand and different measures and dimensions of job performance on the other hand showed that stressors relate to other-rated job performance similarly and in the same direction as it relates to self-rated job performance. Hence, despite slight differences between self-rated and other-rated performance, it seems that employees, if anonymously, rate their own performance similarly to how their supervisors rate them.

\section{Implications for Practice}

Despite these limitations and the implications for future research, the current findings already have important implications practice. First of all, the current study reinforces the importance for organizations to invest in their employees' work engagement. The more vital employees feel and the more absorbed by and dedicated to their work they are, the better they do on all facets of job performance. Furthermore, this initial examination of why engaged workers would be better performers enables us to establish the relation between well-being at work and job performance more in-depth, getting a better grasp which type of performance (i.e., extra-role, in-role, or counterproductive) engagement affects mostly (happy-productive worker hypothesis; Fisher 2003). For instance, a decline in extrarole and in-role behavior at the individual level is likely to indicate a decline in engagement and may offset a decline in the 'harder-to-grasp' outcome performance at the unitor organizational level. Thus, all the reason for managers to intervene and invest in their employees' engagement before outcome performance actually worsens. When managers do not have the means to balance the job demands and resources more adequately to enhance engagement (Schaufeli and Bakker 2004), the current study suggests that managers may also work on employees' open-mindedness first to enhance performance. Of course, further research is necessary to investigate tailor-made interventions regarding open-mindedness.

In sum, while more extensive research is needed in order to fully understand the relation between work engagement and job performance, the current study presents an initial explanation why engaged workers are better performers. In accordance with the recent literature on performance (Koopmans et al. 2011; Reijseger et al. 2012), the present study investigated job performance in a more systematic manner, clarifying more in-depth as to why organizations should focus on investing in the level of work engagement of their employees instead of keeping them merely satisfied (Schaufeli 2011; Taris and Schreurs 2009). Facilitating an open mind at work by stimulating work engagement promotes workers' mental health and optimal functioning. Thus, investing in an engaged workforce means investing in a healthy performing organization.

\section{References}

Amit, A., \& Sagiv, L. (2013). The role of epistemic motivation in individuals' response to decision complexity. Organizational Behavior and Human Decision Processes, 121, 104-117.

Arbuckle, J. L. (1997). Amos users' guide version 4.0. Chicago, IL: Smallwaters Corporation.

Bakker, A. B., Albrecht, S. L., \& Leiter, M. P. (2011). Key questions regarding work engagement. European Journal of Work and Organizational Psychology, 20, 4-28.

Bakker, A. B., \& Bal, P. M. (2010). Weekly work engagement and performance: A study among starting teachers. Journal of Occupational and Organizational Psychology, 83, 189-206. 
Bakker, A. B., \& Demerouti, E. (2008). Towards a model of work engagement. Career Development International, 13, 206-223.

Bakker, A. B., Schaufeli, W. B., Leiter, M. P., \& Taris, T. W. (2008). Work engagement: An emerging concept in occupational health psychology. Work \& Stress, 22, 187-200.

Balducci, C., Schaufeli, W. B., \& Fraccaroli, F. (2011). The jobdemands resources model and counterproductive work behaviour: The role of job-related affect. European Journal of Work and Organizational Psychology, 20, 467-496.

Bandalos, D. L. (2002). The effects of item parceling on goodness-offit and parameter estimate bias in structural equation modeling. Structural Equation Modeling, 9, 78-102.

Berry, C. M., Carpenter, N. C., \& Barratt, C. L. (2012). Do otherreports of counterproductive work behavior provide an incremental contribution over self-reports? A meta-analytic comparison. Journal of Applied Psychology, 97, 613-636.

Bowling, N. A., \& Gruys, M. L. (2010). Overlooked issues in the conceptualization and measurement of counterproductive work behavior. Human Resource Management Review, 20, 54-61.

Brown, S. P., \& Leigh, T. W. (1996). A new look at psychological climate and its relationship to job involvement, effort, and performance. Journal of Applied Psychology, 81, 358-368.

Chirumbolo, A., Mannetti, L., Pierro, A., Areni, A., \& Kruglanski, A. W. (2005). Motivated closed-mindedness and creativity in small groups. Small Group Research, 36, 59-82.

Christian, M. S., Garza, A. S., \& Slaughter, J. E. (2011). Work engagement: A quantitative review and test of its relations with task and contextual performance. Personnel Psychology, 64, 89-136.

Conway, J. M., \& Lance, C. E. (2010). What reviewers should expect from authors regarding common method bias in organizational research. Journal of Business and Psychology, 25, 325-334.

Darr, W., \& Johns, G. (2008). Work strain, health, and absenteeism: A meta-analysis. Journal of Occupational Health Psychology, 13, 293-318.

De Dreu, C. K. W. (2007). Cooperative outcome interdependence, task reflexivity, and team effectiveness: A motivated information processing perspective. Journal of Applied Psychology, 92, 628-638.

De Dreu, C. K. W., Beersma, B., Stroebe, K., \& Euwema, M. C. (2006). Motivated information processing, strategic choice, and the quality of negotiated agreement. Journal of Personality and Social Psychology, 90, 927-943.

Duffy, M. K., Ganster, D. C., \& Shaw, J. D. (1998). Positive affectivity and negative outcomes: The role of tenure and job satisfaction. Journal of Applied Psychology, 83, 950-959.

Elliot, A. J., \& McGregor, H. A. (2001). A $2 \times 2$ Achievement goal framework. Journal of Personality and Social Psychology, 80, $501-519$

Field, A. (2009). Discovering statistics using SPSS. Thousand Oaks, CA: Sage.

Fisher, C. D. (2003). Why do lay people believe that satisfaction and performance are correlated? Journal of Organizational Behavior, 24, 753-777.

Fredrickson, B. L. (2001). The role of positive emotions in positive psychology: The broaden-and-build theory of positive emotions. American Psychologist, 56, 218-226.

Frese, M., Fay, D., Hilburger, T., Leng, K., \& Tag, A. (1997). The concept of personal initiative: Operationalization, reliability and validity in two German samples. Journal of Occupational and Organizational Psychology, 70, 139-161.

Fujita, K., Gollwitzer, P. M., \& Oettingen, G. (2007). Mindsets and pre-conscious open-mindedness to incidental information. Journal of Experimental Social Psychology, 43, 48-61.

Galinsky, A. D., \& Kray, L. J. (2004). From thinking about what might have been to sharing what we know: The effects of counterfactual mind-sets on information sharing in groups. Journal of Experimental Social Psychology, 40, 606-618.

Gilboa, S., Shirom, A., Fried, Y., \& Cooper, C. (2008). A metaanalysis of work demand stressors and job performance: Examining main and moderating effects. Personnel Psychology, 61, 227-271.

Goodman, S. A., \& Svyantek, D. J. (1999). Person-organization fit and contextual performance: Do shared values matter? Journal of Vocational Behavior, 55, 254-275.

Hakanen, J. J., Perhoniemi, R., \& Toppinen-Tanner, S. (2008). Positive gain spirals at work: From job resources to work engagement, personal initiative and work-unit innovativeness. Journal of Vocational Behavior, 73, 78-91.

Halbesleben, J. R. B., \& Wheeler, A. R. (2008). The relative roles of engagement and embeddedness in predicting job performance and intention to leave. Work \& Stress, 22, 242-256.

Hirst, G., Van Knippenberg, D., \& Zhou, J. (2009). A cross-level perspective on employee creativity: Goal orientation, team learning behavior, and individual creativity. Academy of Management Journal, 52, 280-293.

Hoyle, R. H. (1995). The structural equation modeling approach: basic concepts and fundamental issues. In R. H. Hoyle (Ed.), Structural equation modeling, concepts, issues, and applications (pp. 1-15). Thousand Oaks, CA: Sage.

Koopmans, L., Bernaards, C. M., Hildebrandt, V. H., Schaufeli, W. B., de Vet, H. C. W., \& van der Beek, A. J. (2011). Conceptual frameworks of individual work performance: A systematic review. Journal of Occupational and Environmental Medicine, 53, 856-866.

Kruglanski, A. W. (1980). Lay epistemic-logic-process and contents: Another look at attribution theory. Psychological Review, 87, 70-87.

Kruglanski, A. W. (1989). The psychology of being 'right': The problem of accuracy in social perception and cognition. Psychological Bulletin, 106, 395-409.

Kruglanski, A. W., \& Webster, D. M. (1996). Motivated closing of the mind: "Seizing" and "freezing". Psychological Review, 103, 263-283.

Lievens, F., \& Anseel, F. (2004). Confirmatory factor analysis and invariance of an organizational citizenship behaviour measure across samples in a Dutch-speaking context. Journal of Occupational and Organizational Psychology, 77, 299-306.

MacKenzie, S. B., Podsakoff, P. M., \& Fetter, R. (1993). The impact of organizational citizenship behavior on evaluations of salesperson performance. Journal of Marketing, 57, 70-80.

Meier, L. L., \& Spector, P. E. (2013). Reciprocal effects of work stressors and counterproductive work behavior: A five-wave longitudinal study. Journal of Applied Psychology, 98, 529-539.

Motowidlo, S. J., \& Van Scotter, J. R. (1994). Evidence that task performance should be distinguished from contextual performance. Journal of Applied Psychology, 79, 475-480.

Nunnally, J. C., \& Bernstein, I. H. (1994). Psychometric theory (3rd ed.). New York: McGraw-Hill.

Ouweneel, E., Le Blanc, P. M., Schaufeli, W. B., \& Van Wijhe, C. I. (2012). Good morning, good day: A diary study on positive emotions, hope, and work engagement. Human Relations, 65, $1129-1154$.

Penney, L. M., \& Spector, P. E. (2005). Job stress, incivility, and counterproductive work behavior (CWB): The moderating role of negative affectivity. Journal of Organizational Behavior, 26, 777-796.

Podsakoff, P. M., MacKenzie, S. B., Lee, J. Y., \& Podsakoff, N. P. (2003). Common method biases in behavioral research: A critical review of the literature and recommended remedies. Journal of Applied Psychology, 88, 879-903.

Reijseger, G., Schaufeli, W. B., Peeters, M. C. W., \& Taris, T. W. (2012). Ready, set, go! From work engagement to job 
performance. In S. P. Gonçalves (Ed.), Occupational health psychology: From burnout to well-being. London: Scientific \& Academic Publishing Co.

Robinson, S. L., \& Bennett, R. J. (1995). A typology of deviant workplace behaviors: A multidimensional scaling study. The Academy of Management Journal, 38, 555-572.

Roe, R. A. (1999). Work performance: A multiple regulation perspective. In C. L. Cooper \& I. T. Robertson (Eds.), International review of industrial and organizational psychology (Vol. 14, pp. 231-335). Chichester: Wiley.

Schaufeli, W. B. (2011). Waarom bevlogenheid? Is tevredenheid dan niet voldoende? [Why engagement? Is satisfaction insufficient?] Retrieved on [datum] from www.sn.nl/inzicht.

Schaufeli, W. B., \& Bakker, A. B. (2004). Job demands, job resources, and their relation with burnout and engagement: A multi-sample study. Journal of Organizational Behavior, 25, 293-315.

Schaufeli, W. B., Bakker, A. B., \& Salanova, M. (2006). The measurement of work engagement with a short questionnaire: A cross-national study. Educational and Psychological Measurement, 66, 701-716.

Schaufeli, W. B., \& Van Rhenen, W. (2006). About the role of positive and negative emotions in managers' well-being: A study using the Job-related Affective Well-being Scale (JAWS). Gedrag \& Organisatie, 19, 323-344.

Smith, C. A., Organ, D. W., \& Near, J. P. (1983). Organizational citizenship behavior: Its nature and antecedents. Journal of Applied Psychology, 68, 653-663.

Taris, T. W., \& Kompier, M. A. J. (2006). Games researchers play: Extreme-groups analysis and mediation analysis in longitudinal, occupational, and health research. Scandinavian Journal of Work, Environment \& Health, 32, 463-472.

Taris, T. W., \& Kompier, M. A. J. (2014). Cause and effect: Optimizing the designs of longitudinal studies in occupational health psychology. Work \& Stress, 28, 1-4.

Taris, T. W., \& Schreurs, P. J. G. (2009). Well-being and organizational performance: An organizational-level test of the happyproductive worker hypothesis. Work \& Stress, 23, 120-136.

Tjosvold, D. (2008). The conflict-positive organization: It depends upon us. Journal of Organizational Behavior, 29, 19-28.

Tjosvold, D., Tang, M. M. L., \& West, M. (2004). Reflexivity for team innovation in China: The contribution of goal interdependence. Group and Organization Management, 29, 540-559.

Van Beek, I., Hu, Q., Schaufeli, W. B., Taris, T. W., \& Schreurs, B. H. J. (2012). For fun, love, or money: What drives workaholic, engaged, and burned-out employees at work? Applied Psychology: An International Review, 61, 30-55.

Van der Zee, K. I., \& Van Oudenhoven, J. P. (2000). Psychometric qualities of the multicultural personality questionnaire: $\mathrm{A}$ multidimensional instrument of multicultural effectiveness. European Journal of Personality, 14, 291-309.

Webster, D. M., \& Kruglanski, A. W. (1994). Individual differences in need for cognitive closure. Journal of Personality and Social Psychology, 67, 1049-1062.

Wright, T. A., \& Bonett, D. G. (2007). Job satisfaction and psychological well-being as nonadditive predictors of workplace turnover. Journal of Management, 33, 141-160.

Zhou, J., \& George, J. M. (2001). When job dissatisfaction leads to creativity: Encouraging the expression of voice. AMJ, 44, 682-696. 